\title{
Cytoprotective functions of amyloid precursor protein family members in stress signaling and aging
}

\author{
Arpita Kundu*, Andreas Zymny, Steffi Chang, Nelli Röhner, Donat Kögel \\ From Molecular Neurodegeneration: Basic biology and disease pathways \\ Cannes, France. 10-12 September 2013
}

\section{Background}

The amyloid precursor protein (APP) is processed via two different metabolic pathways: the amyloidogenic and the non-amyloidogenic pathway, the latter of which leading to generation of the secreted $\mathrm{N}$-terminal APP fragment sAPP $\alpha$ [1]. Previous studies from our group suggest that SAPP $\alpha$ exerts potent neuroprotective effects and inhibits stress-triggered cell death via modulation of gene expression, as well as by antagonizing different types of neurotoxic stress [2]. It was also observed that the biochemical processing of APP is downregulated during aging which in turn reduced the secretion of sAPP $\alpha$ [3]. Based on these observations, we have studied the potential physiological function of sAPPa/APP and APLPs (APP like proteins) on the regulation of ageassociated, stress induced signaling pathways, apoptosis and senescence.

\section{Materials and methods}

SH-SY5Y, PC12, IMR90 cells were used as cellular models. Depletion of APP, APLP1 (APP like protein 1) and APLP2 (APP like protein 2) in SH-SY5Y cells was achieved by stable lentiviral knockdown. To analyze the protective function of $\operatorname{SAPP} \alpha$, we have used conditioned supernatants of wild type APP overexpressing HEK cells and recombinant His-tagged sAPP $\alpha$ purified from yeast. The cells were treated with SAPP $\alpha$ prior to the addition of different stress stimuli (MG132, epoxomicin, UV, $\mathrm{H}_{2} \mathrm{O}_{2}$ ) after which cell death, gene expression and senescence were analyzed by MTT assays, caspase activity assays, Western blots and X-Gal staining respectively.

\footnotetext{
Experimental Neurosurgery, Neuroscience Center, Goethe University Hospital,
} Frankfurt am Main, Germany

\section{Results}

Our data show that sAPP $\alpha$ can antagonize premature senescence induced by repetitive short term induction of proteasomal stress in IMR-90 cells and apoptosis triggered by prolonged proteasomal stress and other death stimuli in PC12, SH-SY5Y and IMR90 cells which was accompanied by a sAPP $\alpha$-dependent inhibition of the JNK stress signaling pathway. In contrast, no significant changes in cell viability and apoptosis were observed when APP knockdown cells were pretreated with sAPP $\alpha$.

\section{Conclusions}

Our observations suggest that sAPP $\alpha$ can antagonize both apoptosis and cellular senescence and requires expression of holo-APP to mediate its cytoprotective effects. They also support the notion that the physiological function of APP is linked to modulation of neuronal and brain aging.

\section{Acknowledgements}

This study is supported by the German Research Foundation (DFG, FOR1332: Physiological functions of the APP Gene Family in the Central Nervous System)

Published: 13 September 2013

\section{References}

1. Selkoe DJ: Cell biology of protein misfolding: the examples of Alzheimer's and Parkinson's diseases. Nat Cell Bio 2004, 6:1054-1061.

2. Kögel D, Deller $T$, Behl C: Roles of amyloid precursor protein family members in neuroprotection, stress signaling and ageing. Exp Brain Res 2012, 217:471-479.

3. Kern A, Roempp B, Prager K, Walter J, Behl C: Down-regulation of endogenous amyloid precursor protein processing due to cellular aging. J Biol Chem 2006, 281:2405-2413.

doi:10.1186/1750-1326-8-S1-P26

Cite this article as: Kundu et al:: Cytoprotective functions of amyloid precursor protein family members in stress signaling and aging. Molecular Neurodegeneration 2013 8(Suppl 1):P26. 